Proceedings of the 11th Polish-Japanese Joint Seminar on Micro and Nano Analysis, Gniew, September 11-14, 2016

\title{
Corrosion Behavior of Crofer 22APU for Metallic Interconnects in Single and Dual Atmosphere Exposures at $1073 \mathrm{~K}$
}

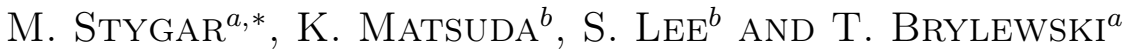

${ }^{a}$ Faculty of Materials Science and Ceramics, AGH University of Science and Technology, Krakow, Poland

${ }^{b}$ Department of Materials Science and Engineering, University of Toyama, Toyama, Japan

To determine the impact of an oxidizing $\mathrm{Ar}-\mathrm{H}_{2}-\mathrm{H}_{2} \mathrm{O}$ /air dual atmosphere on the kinetics and mechanism of oxidation of the Crofer 22APU steel as compared to oxidation in a single atmosphere $\left(\mathrm{Ar}-\mathrm{H}_{2}-\mathrm{H}_{2} \mathrm{O}\right.$ or air), the oxidation kinetics of this steel were investigated both in single and dual reaction atmospheres at $1073 \mathrm{~K}$ during $100,250,500$, and $1000 \mathrm{~h}$ of oxidation. Detailed morphological observations and the results of chemical composition analyses carried out using transmission electron microscopy combined with energy-dispersive X-ray spectroscopy revealed the presence of Fe in the scale formed on the cathode side in the dual atmosphere. Based on morphological observations (scanning- and transmission electron microscopies) and chemical and phase composition analyses (energy-dispersive X-ray spectroscopy and X-ray diffraction, respectively) of the products of oxidation of the Crofer 22APU steel, and on the determined oxidation kinetics, a mechanism describing scale growth on both sides of the steel during its oxidation in conditions involving a gradient of the chemical potential of oxygen and hydrogen was proposed.
\end{abstract}

DOI: 10.12693/APhysPolA.131.1394

PACS/topics: 81.05.Bx, 81.65.Mq, 81.70.-q, 87.64.Ee, 88.30.pn

\section{Introduction}

Solid oxide fuel cells (SOFCs) are highly promising devices that might become efficient sources of electrical energy and heat in the future. The construction of SOFCs requires the application of interconnects, which separate air and fuel flows and provide both electrical contact and mechanical support for the cells in a stack. Interconnect material must meet certain very rigorous requirements, including: a thermal expansion coefficient well-matched to those of the remaining cell components, gas-tightness, high electrical conductivity, good mechanical properties in elevated temperatures, and chemical stability under the conditions specific to SOFC operation.

Chromium-rich ferritic stainless steels (FSS) are currently the most suitable materials used to manufacture metallic interconnects for SOFC stacks [1-3]. Aside from providing structural support for the fuel cell's components and serving as an electrical connector, interconnects also separate the gaseous media, i.e. the fuels $\left(\mathrm{H}_{2}-\right.$ $\mathrm{H}_{2} \mathrm{O}$ or $\mathrm{C}_{n} \mathrm{H}_{2 n-2}-\mathrm{H}_{2} \mathrm{O}$ ) and the oxidant (air or oxygen). This implies that the interconnect is exposed to hightemperature corrosion in an environment which features a gradient of the chemical potential of oxygen and hydrogen, originating from the presence of the oxidation products of $\mathrm{H}_{2}$ fuel in the form of $\mathrm{H}_{2} \mathrm{O}$ on the anode side, and - on the cathode side - oxygen originating from air which undergoes reduction (shown in Fig. 1).

\footnotetext{
*corresponding author; e-mail: stygar@agh.edu.pl
}

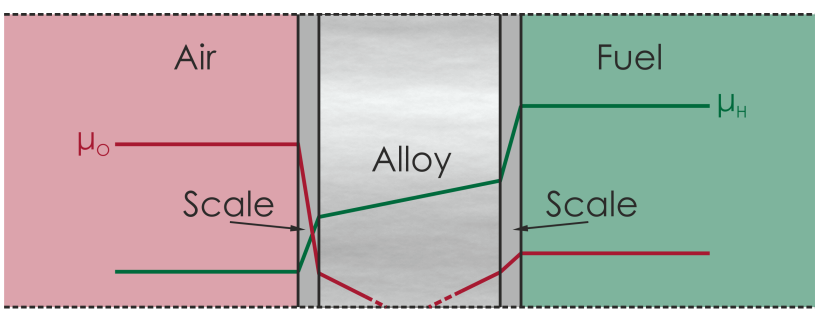

Fig. 1. Gradient of chemical potential in a metallic interconnect at $1073 \mathrm{~K} \mathrm{[4].}$

The research conducted thus far has shown that the oxidation of ferritic steels results in the formation of a compact, double-layer scale consisting of a continuous and thick $\mathrm{Cr}_{2} \mathrm{O}_{3}$ inner layer and a thin $\mathrm{MnCr}_{2} \mathrm{O}_{4}$ outer layer on the surface of FSSs. Moreover, during oxidation in dual atmospheres, an increase in the concentration of iron in the scale layer formed on the part of the steel exposed to air is occasionally observed. However, the results obtained until now do not clearly indicate a direct correlation between this phenomenon and the oxidation conditions or the chromium content in the steel. For example, studies by Nakagawa et al. (2.14-12.12 wt\% Cr) [5] and Yang et al. (AISI430 steel with 16-18 wt.\% Cr) [6] found that the gradient of chemical potential significantly affects the formation of iron oxides and the enrichment of the scale on the cathode side with Fe. This is explained by the fast diffusion of iron via the increased number of defects in the $\mathrm{Cr}_{2} \mathrm{O}_{3}$ structure, which is caused by the incorporation of hydrogen into its crystal lattice. On the other hand, the research conducted by Kurokawa et al. (SUS430 steel with 16.31 wt\% Cr) [4] and Stygar et al. 
(DIN50049 steel with 24.55 wt\% Cr) [7] indicate the lack of either a significant concentration of iron in the scale formed on the cathode side or any correlation between the above-mentioned gradient of chemical potential and the chromium content in the steel or the relative contribution of hydrogen/water vapor in the mixture supplied to the sample surface on the anode side. It is worth mentioning that in experiments performed in an environment that reflects the operating conditions of SOFC, considerable attention was paid to the applied voltage [8, 9] as well as the "contamination" of the air that fuels the anode space of SOFCs with water vapor $[8,10,11]$. However, the majority of such studies [12-16] that concerned the Crofer 22APU steel oxidized in a dual atmosphere feature relatively brief oxidation times ranging from 100 to $300 \mathrm{~h}$.

Consequently, it was necessary to perform detailed studies of the microstructure of scales formed on the Crofer 22APU steel oxidized in a $\mathrm{Ar}-\mathrm{H}_{2}-\mathrm{H}_{2} \mathrm{O}$ /air dual atmosphere for at least $1000 \mathrm{~h}$, and to undertake an attempt at the explanation of the oxidation mechanism of this steel based on the obtained data.

\section{Materials and experimental setup}

The material used during research was the Crofer 22APU steel with the designations W.-No. 1.4760 X1CrTiLa22 (in the DIN EN standard) or UNS S44535 (per the ASTM standard) [17]. This commercially available ferritic stainless steel is manufactured by ThyssenKrupp VDM GmbH using a license granted by Forschungszentrum Jülich, and it is designed for application in solid oxide fuel cell interconnects. The chemical composition of the investigated steel, expressed in wt\%, is presented in Table I.

TABLE I

Chemical composition of the Crofer 22 APU steel (wt\%).

\begin{tabular}{c|c|c|c|c|c|c|c|c|c}
\hline \hline Element & $\mathrm{Fe}$ & $\mathrm{Cr}$ & $\mathrm{Mn}$ & $\mathrm{Ti}$ & $\mathrm{Si}$ & $\mathrm{C}$ & $\mathrm{P}$ & $\mathrm{S}$ & $\mathrm{La}$ \\
\hline \multirow{2}{*}{ from [17] } & bal. & 22.0 & 0.30 & 0.03 & 0 & 0 & 0 & 0 & 0.04 \\
& & 24.0 & 0.80 & 0.20 & 0.50 & 0.03 & 0.05 & 0.02 & 0.20 \\
as received & 76.819 & 22.0 & 0.50 & 0.08 & 0.50 & 0.005 & 0.016 & 0.02 & 0.06
\end{tabular}

Steel samples in the form of discs $(\varnothing 28 \mathrm{~mm}$; thickness of $1 \mathrm{~mm}$ ) were obtained through the electrical discharge machining (EDM) of the steel sheet. The cutting was performed with a brass wire, with paraffin oil acting as a dielectric. The obtained samples were then polished using the standard Struers procedure (Largo/Dap/Nap), with the last stage of polishing performed with a $1 \mu \mathrm{m}$ diamond paste. The samples were then ultrasonically degreased and washed in acetone and ethanol.

The experimental setup for sample oxidation in an $\mathrm{Ar}-$ $\mathrm{H}_{2}-\mathrm{H}_{2} \mathrm{O}$ /air dual atmosphere - as shown in Fig. 2 consisted of a reaction furnace, gas flowmeter system and a water vapor saturator. A $10 \% \mathrm{Ar}-\mathrm{H}_{2}$ mixture was channeled into the saturator (with double-distilled water), which was dipped into the cooling agent inside the cryostat chamber. The mixture was then saturated with water vapor until its partial pressure $\left(p\left(\mathrm{H}_{2} \mathrm{O}\right)\right)$ reached a level of $6.22 \times 10^{-3} \mathrm{~atm}$ at the temperature of $0^{\circ} \mathrm{C}$. To prevent the water vapor from undergoing condensation on its way to the reaction chamber, the whole ducting pipe was covered with thermal isolation. Before the experiment, the oxygen partial pressure of the $\mathrm{H}_{2} / \mathrm{H}_{2} \mathrm{O}$ gas mixture was measured with the MX6 multi-gas detector at points of inlet and outlet of the fuel side of the furnace.

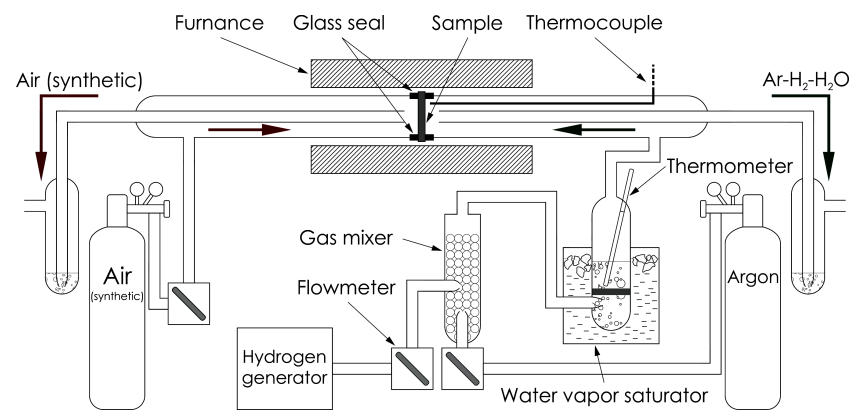

Fig. 2. Experimental setup for oxidation tests in an Ar $-\mathrm{H}_{2}-\mathrm{H}_{2} \mathrm{O} /$ air dual atmosphere.

The most vital part of the experimental setup was composed of fused quartz. The setup was constructed out of two quartz tubes, which allowed different atmospheres to be induced on each of the two sides of the examined samples. The examined materials were placed in the isothermal heating zone inside the furnace and the system was sealed using a sealant resistant to high temperatures of up to $1500^{\circ} \mathrm{C}$; the sealant was based on sodium silicate. Long-term tests of sealant under the experimental conditions involving oxygen or hydrogen showed perfect gastightness at high temperature.

The studies were conducted in isothermal conditions and at a temperature of $800^{\circ} \mathrm{C}$. The afore-mentioned dual-atmosphere conditions were applied. The samples were heated for $100,250,500$, or $1000 \mathrm{~h}$. The oxidation process of the studied steel follows the parabolic rate law. The calculated thickness values of the oxide scales grown after these oxidation times and the corresponding values of the parabolic rate constant are available elsewhere [18].

The phase composition was analysed by means of the PANalytical X'Pert Pro PW 3710 X'Celerator, using $\mathrm{Cu} K_{\alpha}$ radiation; data was collected over a $2 \Theta$ range of $20-90^{\circ}$, with a step of $0.008^{\circ}$ and an $80 \mathrm{~s}$ count. Observations of the surface morphology and cross-sections of the steel after high-temperature oxidation tests were conducted using a scanning electron microscope (FEI Nova NanoSEM 200, JEOL JSM-6610LV) coupled with an EDAX Genesis XM X-ray microanalyzer, which was used to examine its chemical composition. More detailed morphological observations and chemical composition analyses were carried out using transmission electron microscopy combined with energy-dispersive X-ray spectroscopy (TEM-EDS), performed by means of TOPCON EM002B, JEOL JEM-4010HT (operating at $400 \mathrm{keV}$, with the camera constant of $0.10694739 \mathrm{~nm})$. The sam- 
ples for TEM cross-sectional observations were prepared via the focused ion beam method (FB-2100, HITACHI) with a voltage of $40 \mathrm{keV}$, and with the use of gallium ions.

\section{Results and discussion}

To allow the identification of the phase composition of corrosion products, X-ray diffraction studies (XRD) were performed on the surface the Crofer 22APU ferritic steel obtained after $100,250,500$, or $1000 \mathrm{~h}$ of oxidation. Two series of measurements were carried out. The first series was performed for each of the two sides of samples exposed to a dual atmosphere, i.e. on the air side and the side with the $\mathrm{Ar}-\mathrm{H}_{2}-\mathrm{H}_{2} \mathrm{O}$ mixture. The second series was performed to obtain reference data for the corresponding single atmospheres. The experiments conducted for increasingly long oxidation times showed that the scales formed on the steel comprised mostly $\mathrm{Cr}_{2} \mathrm{O}_{3}$ and the $(\mathrm{Mn}, \mathrm{Cr})_{3} \mathrm{O}_{4}$ manganese-chromium spinel. These two phases were found in all examined corrosion products, regardless of the type of atmosphere and the oxidation time. Reflections observed at the $2 \Theta$ angles of $44.44^{\circ}, 64.78^{\circ}$ and $82.0^{\circ}$ corresponded to the $\alpha$-Fe phase originating from the metallic substrate located underneath the scale.

Figure 3 shows the X-ray diffraction patterns obtained for the Crofer 22APU samples after $1000 \mathrm{~h}$ of oxidation at $800{ }^{\circ} \mathrm{C}$, either in an $\mathrm{Ar}-\mathrm{H}_{2}-\mathrm{H}_{2} \mathrm{O} /$ air dual atmosphere from the air side (Fig. 3a), or in a single atmosphere consisting of air (Fig. 3b). As can be seen, these patterns are nearly identical. The $\mathrm{SiO}_{2}$ and $\mathrm{Al}_{2} \mathrm{Si}_{2} \mathrm{O}_{7}$ phases detected in the steel oxidized in the dual atmosphere (Fig. 3a) can be attributed to the remnants of the non-reactive ceramic sealant. The presence of iron (in the form of its oxide) in the scale would be hard to verify based solely on XRD data, since iron oxide has a similar reference standard to chromium, which is the main component of the scale. As illustrated in Fig. 3, as many as eight main peaks of $\mathrm{Fe}_{2} \mathrm{O}_{3}$ overlap with those of $\mathrm{Cr}_{2} \mathrm{O}_{3}$. Some doubts can arise only with regard to reflections for large angles in the area with pronounced separation. The ICDD pattern for $\mathrm{Fe}_{2} \mathrm{O}_{3}$ appears to correspond to reflexes for the $62.8^{\circ}$ and $64.4^{\circ}$ angles better than the ICDD pattern specific to $\mathrm{Cr}_{2} \mathrm{O}_{3}$.

It is worth adding that in a study by Huang et al. [12], featuring $100 \mathrm{~h}$ of oxidation in a dual atmosphere, no additional phases were found either on the cathode side or the anode side, which is consistent with the abovepresented findings.

The results of diffraction studies were verified by performing a number of chemical composition analyses for selected areas located on the cross-section of the scale formed on the Crofer 22APU steel after $1000 \mathrm{~h}$ of oxidation at $800^{\circ} \mathrm{C}$. Figure 4 shows the results of EDS line scan analyses performed for samples oxidized either in an $\mathrm{Ar}-\mathrm{H}_{2}-\mathrm{H}_{2} \mathrm{O}$ /air dual atmosphere - from the air side (Fig. 4a), or in a single atmosphere consisting of air

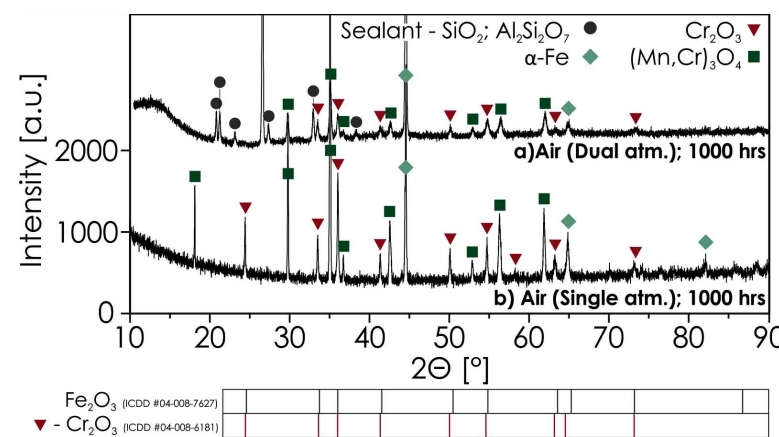

Fig. 3. X-ray diffraction patterns obtained after $1000 \mathrm{~h}$ of oxidation at $800{ }^{\circ} \mathrm{C}$ in: (a) $\mathrm{Ar}-\mathrm{H}_{2}-\mathrm{H}_{2} \mathrm{O}$ /air dual atmosphere - air side, (b) single atmosphere consisting of air.

(Fig. 4b). In this material, the iron and chromium content both within the metallic substrate area and in the internal oxidation zone was similar to that in the steel prior to oxidation. In the outer part of the scale, which was composed predominantly of the $(\mathrm{Mn}, \mathrm{Cr})_{3} \mathrm{O}_{4}$ phase, a small amount of iron (3.5 at.\%) was observed. After accounting for the measurement error and other factors that affect the reliability of measurements, it can be concluded that - in the case of the scale formed in the dual atmosphere, on the air side - the amount of Fe in the outer part of the scale is slightly larger than the Fe content in the corresponding fragment of the scale formed in the single atmosphere consisting of air.

To verify and clarify the results obtained via SEMEDS, the chemical composition profiles of the oxide scale were also examined using the TEM-EDS point scan technique, as shown in Fig. 5.

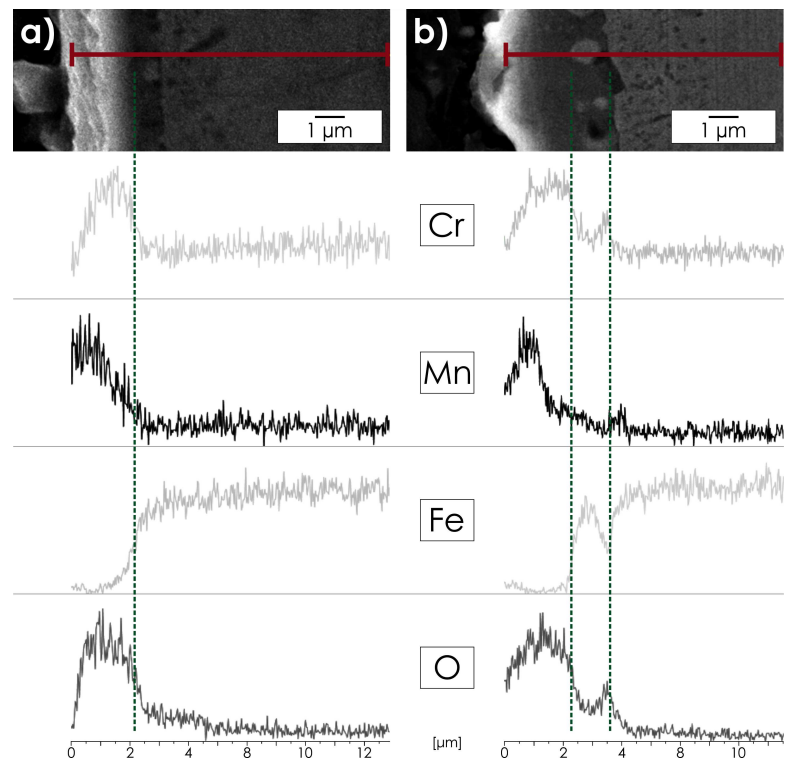

Fig. 4. EDS line scan data obtained for cross-sections of Crofer $22 \mathrm{APU}$ steel oxidized in $800^{\circ} \mathrm{C}$ in $1000 \mathrm{~h}$, along the lines indicated in the SEM microphotographs in: (a) $\mathrm{Ar}-\mathrm{H}_{2}-\mathrm{H}_{2} \mathrm{O}$ /air dual atmosphere - air side, (b) single atmosphere consisting of air. 

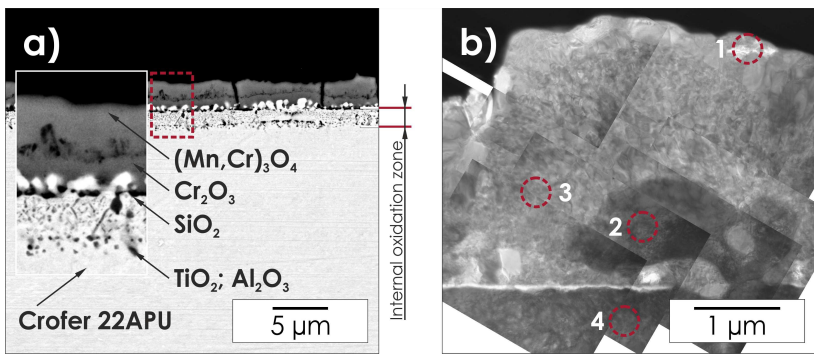

Fig. 5. (a) SEM microphotographs of a cross-section of a scale formed on the Crofer 22APU on the air side after $1000 \mathrm{~h}$ of oxidation in an $\mathrm{Ar}-\mathrm{H}_{2}-\mathrm{H}_{2} \mathrm{O} /$ air dual atmosphere at $800^{\circ} \mathrm{C}$; (b) areas for which TEM-EDS point scan analysis was performed.

According to the data collected in Table II, the outer scale layer, represented by point no. 1 in Fig. 5 b, contains $\mathrm{Mn}, \mathrm{Cr}$, and $\mathrm{O}$ in a ratio typical of the $(\mathrm{Mn}, \mathrm{Cr})_{3} \mathrm{O}_{4}$ manganese-chromium spinel. In the inner layer, near the scale/metal interface, columnar and spherical metallic inclusions fused with the metallic substrate were observed (Fig. 5a). Their chemical composition determined via TEM-EDS point scan analysis performed for point no. 2, was different than that observed in the case of the metallic substrate (point no. 4), since it did not contain alloy additions (Table II). The mechanism underlying the formation of these coarse-crystalline precipitates rich in iron is connected to the compressive stress in the metallic phase due to the presence of $\mathrm{Al}_{2} \mathrm{O}_{3}$ and $\mathrm{SiO}_{2}$ precipitates formed in the internal oxidation zone; a molar volume of these precipitates is higher than that of the studied steel. The chemical composition analysis conducted for the middle part of the scale (point no. 3) revealed that this layer is composed mostly of $\mathrm{Cr}_{2} \mathrm{O}_{3}$, while also confirming the presence of $\mathrm{Fe}$ (Table II). The Fe content determined for four corresponding measurement points ranged from 3.7 to 4.3 at.\%.

TABLE II

The results of EDS quantitative analysis of a scale formed on the air side after $1000 \mathrm{~h}$ of oxidation in an $\mathrm{Ar}-\mathrm{H}_{2}-\mathrm{H}_{2} \mathrm{O} /$ air dual atmosphere at $800^{\circ} \mathrm{C}$.

\begin{tabular}{c|c|c|c|c|c|c|c|c}
\hline \hline Point & Fe & Cr & Mn & Al & Ti & Si & La & O \\
\hline 1 & - & 22.9 & 25.6 & - & - & - & - & 51.5 \\
2 & 79.5 & 20.5 & - & - & - & - & - & - \\
3 & 4.2 & 35.5 & - & 0.3 & - & 2.0 & - & 58.0 \\
4 & 69.1 & 20.8 & - & 7.1 & 0.4 & 0.6 & 0.2 & 1.8
\end{tabular}

Figure 6 shows the bright-field TEM image of a crosssection of the Crofer 22APU steel oxidized in the dual atmosphere $\left(\mathrm{Ar}-\mathrm{H}_{2}-\mathrm{H}_{2} \mathrm{O}\right.$ side $)$ and the corresponding selected area electron diffraction patterns (SAEDPs). The scale was very dense and its thickness was about $4.6 \mu \mathrm{m}$. Point no. 1 in Fig. 6 corresponds to the $\mathrm{Mn}-\mathrm{Cr}$ spinel phase, with the corresponding $[-1-1-2]$ zone axis pattern. The diffraction pattern for point no. 2 revealed the formation of a non-homogeneous oxide scale consisting mainly of chromium(III) oxide; however, the observed polycrystalline ring patterns likely correspond to other oxides, i.e. $\mathrm{Fe}_{2} \mathrm{O}_{3}, \mathrm{Al}_{2} \mathrm{O}_{3}$, or $\mathrm{SiO}_{2}$. The diffraction patterns for points no. 3 and 4 were typical of the $\mathrm{Fe}-\mathrm{Cr}$ phase.

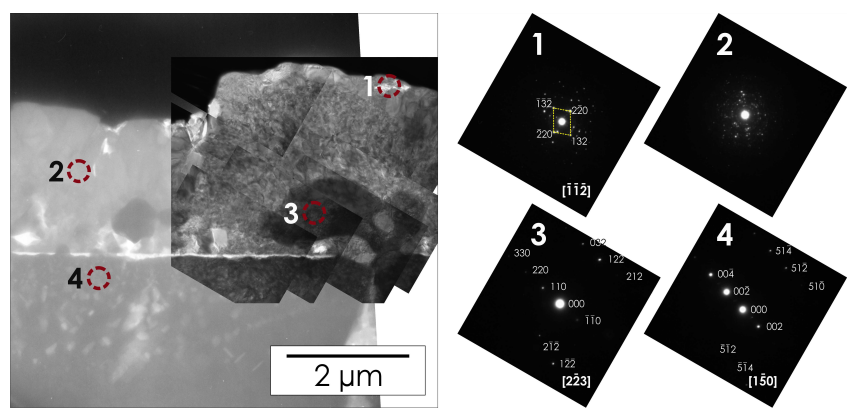

Fig. 6. TEM image of a sample oxidized for $1000 \mathrm{~h}$ in a dual atmosphere $\left(\mathrm{Ar}-\mathrm{H}_{2}-\mathrm{H}_{2} \mathrm{O}\right.$ side $)$ at $800^{\circ} \mathrm{C}$. SAED patterns: (1) $(\mathrm{Mn}, \mathrm{Cr})_{3} \mathrm{O}_{4},(2) \mathrm{Fe}_{2} \mathrm{O}_{3} / \mathrm{Cr}_{2} \mathrm{O}_{3}$, and $(3,4)$ $\mathrm{Fe}-\mathrm{Cr} /$ phase.

The obtained results seem to confirm the influence of the gradient of chemical potential on the formation of iron oxides and the enrichment of the scale on the cathode side with Fe. Literature data indicate that the $\mathrm{Fe}$ diffusion coefficient in the $\mathrm{Cr}_{2} \mathrm{O}_{3}$ crystal lattice is significantly higher than the diffusion coefficient of $\mathrm{Cr}$ [19]. In a dual atmosphere, the hydrogen in the $\mathrm{Ar}-\mathrm{H}_{2}-\mathrm{H}_{2} \mathrm{O}$ mixture diffuses into the metallic phase, in the direction of the opposite side in contact with air, and then dissolves in chromium, increasing the number of its structural defects; as a result, the diffusion coefficient of $\mathrm{Fe}$ in chromium increases [14]. This can be explained as follows. Due to the high diffusivity of hydrogen in chromium-rich ferritic steel [20], the adsorption of this element on the surface of chromium occurs as early as at the initial stage of oxidation, when the scale is relatively thin. Since the diffusion coefficient of hydrogen in ferritic steel is extremely high, i.e. $D=1.6 \times 10^{-2} \mathrm{~cm}^{2} \mathrm{~s}^{-1}$ at $800{ }^{\circ} \mathrm{C}[20]$, the time it takes for hydrogen to migrate through steel with a thickness of $2 \mathrm{~mm}$ to the air side, as calculated from the known Einstein dependence

$$
d=\sqrt{D t}
$$

is just $3 \mathrm{~s}$. Consequently, even at the early oxidation stage, hydroxide cations $\left(\mathrm{OH}_{\mathrm{O}}^{\bullet}\right)$ form in the anion sublattice of chromium when the concentration of hydrogen is very high [21]. Depending on the type of $\mathrm{Cr}_{2} \mathrm{O}_{3}$ defect structure, this process can be expressed (using the Kröger-Vink notation [22]) via one of the following reactions:

$$
\begin{aligned}
& \mathrm{H}+\mathrm{O}_{\mathrm{O}}^{x}+\mathrm{h}^{\bullet}=\mathrm{OH}_{\mathrm{O}}^{\bullet}, \\
& \mathrm{H}+\mathrm{O}_{\mathrm{O}}^{x}=\mathrm{OH}_{\mathrm{O}}^{\bullet}+\mathrm{e}^{\prime} .
\end{aligned}
$$

Assuming that in a sufficiently thin layer of chromium formed in air, ordinary cation vacancies and electron holes constitute the predominant type of defects, the defect formation reaction can be represented by the following quasi-chemical equation: 


$$
\frac{3}{2} \mathrm{O}_{2} \leftrightarrow 2 \mathrm{~V}_{\mathrm{Cr}}^{\prime \prime \prime}+6 \mathrm{~h}^{\bullet}+3 \mathrm{O}_{\mathrm{O}}^{x},
$$

which allows the electronegativity condition of the $\mathrm{Cr}_{2} \mathrm{O}_{3}$ lattice to be formulated as follows:

$$
\left[\mathrm{h}^{\bullet}\right]+\left[\mathrm{OH}_{\mathrm{O}}^{\bullet}\right]=3\left[\mathrm{~V}_{\mathrm{Cr}}^{\prime \prime \prime}\right] \text {. }
$$

This implies an increases in the concentration of tripleionized chromium vacancies in this oxide and the subsequent increase in the diffusivity of the constituents of the investigated steel, i.e. Fe and Mn. The main assumptions of the proposed mechanism are presented in Fig. 7.

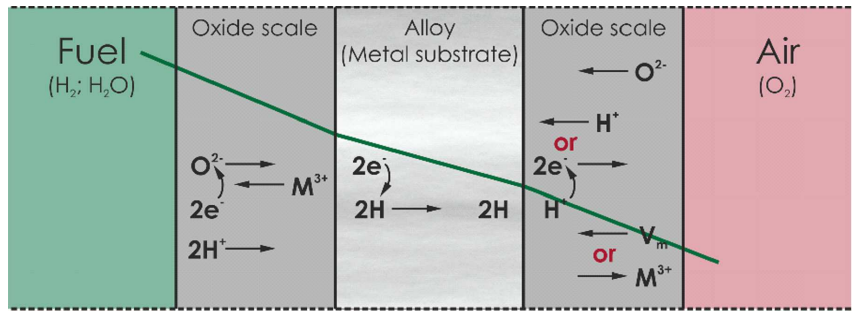

Fig. 7. Model of transport mechanism (Eqs. (2) and (5)) in ferritic steels oxidized under conditions involving a gradient of chemical potential.

\section{Conclusions}

The presented microstructural studies of the Crofer 22APU oxidized in a $\mathrm{Ar}-\mathrm{H}_{2}-\mathrm{H}_{2} \mathrm{O} /$ air dual atmosphere prove that the oxidation process is different than in the case of single atmospheres. The TEM-EDS examination of the sample confirmed that the presence of hydrogen is associated with an increased concentration of Fe in oxidation products formed on the steel exposed to the air side of the dual atmosphere. This can be explained by the fast diffusion of this element into $\mathrm{Cr}_{2} \mathrm{O}_{3}$ and the higher concentration of defects caused by the incorporation of hydrogen into the chromium crystal lattice.

\section{Acknowledgments}

Financial support from the National Science Centre for PRELUDIUM 6, project no. 2013/11/N/ST5/01391 (reg. number), is gratefully acknowledged.

\section{References}

[1] W.J. Quadakkers, J. Piron-Abellan, V. Shemet, L. Singheiser, Mater. High Temp. 20, 115 (2003).
[2] J.W. Fergus, Mater. Sci. Eng. A 397, 271 (2005).

[3] T. Brylewski, M. Nanko, T. Maruyama, K. Przybylski, Solid State Ion. 143, 131 (2001).

[4] H. Kurokawa, K. Kawamura, T. Maruyama, Solid State Ion. 168, 13 (2004).

[5] K. Nakagawa, Y. Matsunaga, T. Yanagisawa, Mater. High Temp. 18, 51 (2001).

[6] Z.G. Yang, K.S. Weil, D.M. Paxton, J.W. Stevenson, Electrochem. Solid-State Lett. 6, B35 (2003).

[7] M. Stygar, T. Brylewski, A. Kruk, K. Przybylski, Solid State Ion. 262, 449 (2014).

[8] M.R. Ardigo, I. Popa, L. Combemale, S. Chevalier, F. Herbst, P. Girardon, Int. J. Hydrogen Energy 40, 5305 (2015).

[9] K. Kawamura, T. Nitobe, H. Kurokawa, M. Ueda, T. Maruyama, J. Electrochem. Soc. 159, B259 (2012).

[10] Y. Zhao, J.W. Fergus, J. Electrochem. Soc. 159, C109 (2012).

[11] M.E. Leonard, P.E. Gannon, W. Shong, Ch. Liu, Int. J. Hydrogen Energy 39, 15746 (2014).

[12] W. Huang, S. Gopalan, U.B. Pal, S.N. Basu, ECS Trans. 7, 2379 (2007).

[13] P. Piccardo, M. Viviani, F. Perrozzi, R. Spotorno, S.A. Ansar, R. Costa, in: Proc. European Fuel Cell Forum 2012, A1215: 109 (2012), Lucerne (Switzerland), 2012.

[14] Z. Yang, M.S. Walker, P. Singh, J.W. Stevenson, T. Norby, J. Electrochem. Soc. 151, B669 (2004).

[15] R. Amendola, P. Gannon, B. Ellingwood, K. Hoyt, P. Piccardo, P. Genocchio, Surf. Coat. Technol. 206, 2173 (2012)

[16] Z. Yang, G. Xia, M.S. Walker, Ch. Wang, J.W. Stevenson, P. Singh, Int. J. Hydrogen Energy 32, 3770 (2007).

[17] Crofer 22 APU - Material Data Sheet No. 4046 , ThyssenKrupp VDM, 2010.

[18] M. Stygar, J. Dąbrowa, P. Dziembaj, T. Brylewski, J. Mater. Eng. Perform. 26, 540 (2016).

[19] M.G.C. Cox, B. McEnaney, V.D. Scott, Philos. Mag. 10, 839 (1972).

[20] S.K. Yen, Y.C. Tsai, J. Electrochem. Soc. 143, 2736 (1996).

[21] X. Tan, K. Li, Chem. Eng. Sci. 55, 1213 (2000).

[22] F.A. Kröger, H.J. Vink, Solid State Phys. 3, 307 (1956). 